\title{
A two year update of a regional survey of the training of junior psychiatrists in behavioural psychotherapy
}

\author{
LyNNe M. DRummond, Consultant Psychiatrist and Senior Lecturer in Behavioural \\ Psychotherapy; and AsHOK V. BHAT, Honorary Lecturer in Biostatistics, \\ St George's Hospital Medical School, Cranmer Terrace, London SW17 0RE
}

In April 1987 the Bulletin of the Royal College of Psychiatrists published the results of a survey of the training of junior psychiatrists in behavioural psychotherapy in the South West Thames Region (Drummond \& Bhat, 1987). This survey reported the experience of trainees based at 10 postgraduate teaching rotations in the Region. The survey was conducted shortly after the appointment of a new peripatetic senior lecturer. Prior to this appointment there had been no regular senior lecturer teaching in behavioural psychotherapy in the Region for at least one year. The paper demonstrated that the majority of trainees had received little or no previous teaching or supervision in behavioural psychotherapy. It also demonstrated that trainees welcomed the introduction of such teaching and that their knowledge of the subject improved significantly after three teaching sessions held at monthly intervals. However, after this short time only $17.1 \%$ of the trainees reported that they had started to use any of the techniques they had learned in clinical practice.

Behavioural psychotherapy consists of a number of therapeutic techniques which can be applied in certain clinical situations (Marks, 1981). For this reason, it seemed vital to ensure that trainees utilised the knowledge they had gained about behavioural treatment in clinical practice. This paper is an update on the previous survey and describes the trainees' performances in behavioural psychotherapy two years after the commencement of regular teaching in the Region ( 21 months after the end of the previously reported survey).

\section{The study}

\section{The sample}

The initial survey included 10 of the 11 postgraduate teaching rotations in the Region. One rotation was excluded as the clinical tutor declined the offer of any additional teaching in behavioural psychotherapy, believing that these trainees already had sufficient experience in this field provided locally. The present paper also includes the same 10 rotations.

Questionnaires (described below) were sent by post to each of the junior doctors on the 10 rotations at the end of
December 1987. In addition, analyses of the data are performed on this original sample and also including trainees working at the teaching hospital. In the original survey, trainees working in Wandsworth and Merton Health District, which is served by St George's and its associated teaching hospitals, were excluded from the sample. The current survey analyses the results of these two groups separately.

\section{Teaching sessions}

The teaching sessions are a minimum of $1.5-2$ hours long and are held at eight of the hospitals in the Region, as well as sessions being held at St George's Hospital which are open to all trainees as well as those working in Wandsworth and Merton District.

A total of 18 sessions have been held over the past 24 months at each of the eight hospitals in the Region and 38 sessions at St George's Hospital. As well as the teaching sessions held at each of the hospitals, trainees who have patients in active behavioural treatment have been encouraged to make additional appointments for individual supervision with the senior lecturer, if required. For those trainees who are based in the periphery of the Region, this supervision has often been performed by telephone contact with the senior lecturer. Generally, clinical psychologists have not been able to provide additional supervision for trainees, although at two peripheral hospitals and also in Wandsworth and Merton, this has also been available.

The initial seven sessions contained four elements.

(a) Lecture of approximately 30 minutes in length. The topics covered were (i) anxiety and phobic disorders; (ii) obsessive-compulsive disorders; (iii) application and use of behavioural psychotherapy; (iv) behavioural marital therapy; (v) treatment of sexual dysfunction; (vi) behavioural analysis, assessment of suitability for treatment and measurement.

(b) Video demonstration of a behavioural treatment session (when applicable and available).

(c) Questions and discussion.

(d) Supervision or role play of clinical cases (Portable video camera used for feedback to trainees).

Following these seven sessions, three session were devoted to supervision and role play of behavioural techniques. For the subsequent sessions trainees have been asked to present a case history of a patient they would like to treat using behavioural psychotherapy. Then, the patient is seen in the session by the senior lecturer and trainees (provided, of course, that the patient consents to this interview). Finally, discussion is held between the trainees and senior lecturer about the measures to be used to assess progress, the therapeutic strategies to be applied and an 
estimate of the amount of therapist's time the patient is liable to require

\section{Questionnaires}

The detailed content of the questionnaires is also described in an earlier paper (Drummond \& Bhat, 1987). Every SHO and registrar working in the region attached to the 10 teaching rotations involved with the behavioural psychotherapy teaching was sent two questionnaires by post which they were asked to return. Trainees who wished to remain anonymous were informed they could do this by not completing their name on the forms.

Two questionnaires were administered.

\section{Background information questionnaire}

This asked about the stage of training in psychiatry and experience in using behavioural psychotherapy techniques.

\section{Final questionnaire}

This consisted of visual analogue scales which asked how useful-useless; boring-interesting; relevant to clinical practice-not relevant to clinical practice, relevant to MRCPsych-not relevant to MRCPsych the sessions and their components were felt to be. Trainees were also asked if they had been prompted to read about behavioural psychotherapy and intended to continue attending the sessions.

\section{Findings}

\section{Description of the sample}

Questionnaires were sent to 87 registrars and SHOs in psychiatry based at 29 different institutions. Twenty-nine $(33.3 \%)$ of the trainees are based in Wandsworth and Merton Districts at any one six-month rotation period. Forty-six (52.8\%) of the trainees were on one of the St George's Hospital training schemes, although not necessarily based in Wandsworth and Merton at the time of the survey. For brevity, these doctors are described as "St George's trainees" in the present paper.

Fifty-seven trainees returned the questionnaires $(65.5 \%)$. The return rate was similar for those trainees on rotations attached to St George's Hospital $(65.2 \%)$ and those on other rotations $(65.8 \%)$. For the purposes of data analysis it was assumed that the 30 trainees who did not return the questionnaires had not attended any sessions and that they had no behavioural psychotherapy experience. The following results are therefore likely to be an underestimate of the behavioural experience of trainees in the Region.

The respondents were mainly registrars and only 15 $(26.3 \%)$ SHOs. The majority had been working in psychiatry for between one and three years $(52.6 \%)$ and $31.6 \%$ had been in psychiatry for more than three years.

\section{Behavioural psychotherapy experience and comparison of St George's and other trainees}

Thirty-seven trainees had treated at least one patient using behavioural psychotherapy. This represented $42.5 \%$ of the total sample. Of trainees attached to a St George's rotation, $55.6 \%$ had experience of behavioural psychotherapy treat- ment compared with $28.6 \%$ of other trainees. Using the continuity adjusted chi-square test, this difference between the teaching and non-teaching hospital trainees was signifcant $(P<0.01)$. Five trainees on a St George's rotation had worked in the Behavioural Psychotherapy Unit with the senior lecturer during the two years preceding the present survey. When these trainees were excluded from the analysis, $50.0 \%$ of St George's trainees had treated a patient using behavioural psychotherapy which was still a signifcantly greater proportion of trainees gaining this experience $(P<0.05)$.

This difference between the St George's and other trainees was reflected in the frequency of treating various groups of patients. St George's trainees were much more likely to have experience of treating social phobic patients $(24.4 \%$ v. $2.4 \% ; P<0.01)$; obsessive-compulsive neurosis $(24.4 \%$ v. $7.1 \% ; P<0.05)$ and social skills deficits $(15.6 \%$ v. $2.4 \% ; P<0.05$ )

\section{Final questionnaire}

Overall, the trainees reported that they found the sessions useful (82.9\%; s.d. 15.2); interesting (80.3\%; s.d. 16.4); relevant to clinical practice $(76.8 \%$; s.d. 22.0$)$; and relevant to MRCPsych (70.9\%; s.d. 26.5). There was no significant difference in the evaluation of the sessions by St George's and other trainees.

The majority of trainees who returned the questionnaires had attended four or more sessions $(75.5 \%$, i.e. $48 \%$ of total sample). Forty ( $75.5 \%$, i.e. $46 \%$ of total sample) of these doctors reported that the sessions had prompted them to read further about behavioural psychotherapy and 45 $(84.9 \%$, i.e. $51.7 \%$ of total sample) that they had used some of the techniques in clinical practice even if they had not embarked on formal supervised behavioural treatment. Forty-seven $(90.4 \%$, i.e. $54.0 \%$ of total sample) of the respondents reported that they intended to continue attending the teaching session.

\section{Comparison of 1986 and 1988 data}

The data from the present survey were then compared with similar data from a survey performed 21 months earlier (Drummond \& Bhat, 1987). As the original data had been obtained from trainees who were not working in the teaching district at the time of that survey, doctors working in Wandsworth and Merton were excluded from the present data for the purposes of comparison. Whereas in 1986 only $17.1 \%$ of these trainees had treated a patient using behavioural psychotherapy, $42.5 \%$ had in the present survey. This result was highly significant $(P<0.001)$. There was an increase in the treatment of most conditions amenable to behavioural treatment by trainees, but this was most marked in the more common conditions such as agoraphobia.

\section{Comment}

The present paper demonstrates that two years after the introduction of regular teaching and supervision, approximately $25 \%$ more of the junior psychiatrists within the South West Thames region were treating patients using behavioural psychotherapy than 
previously. It has frequently been assumed that the reason why many junior doctors do not gain behavioural experience is that they believe these treatments are best dealt with by clinical psychologists. The flaw in this belief has been discussed elsewhere (Marks, 1981). That junior doctors can learn and apply behavioural skills in their clinical practice is shown by our findings.

Despite this overall increase in the use of behavioural psychotherapy, almost twice as many St George's trainees gained this experience compared with other trainees. One reason for this could be the availability of suitable cases. The presence of the Regional Behavioural Psychotherapy Unit in Wandsworth makes it easier for St George's trainees to gain access to appropriate patients. However, as at least $10 \%$ of psychiatric out-patients have been shown to be suitable for behavioural psychotherapy (Marks, 1981), this would not appear to be the whole answer. Undoubtedly, access to a teacher for advice and help is more easily obtained if trainees are familiar with the teacher's work place and schedule. Also, St George's interest in psychological treatments has been well publicised (Crisp, 1977; Hafner, Lieberman \& Crisp, 1977; Lieberman, Hafner \& Crisp, 1978; Stead et al, 1980; Crisp et al, 1987; Drummond \& Bhat, 1987) and may attract trainees with a particular interest in all types of psychotherapy.

Our results show that provision of behavioural psychotherapy teaching and supervision is welcomed and utilised by junior doctors in the region. The Royal College of Psychiatrists recognises the importance of behavioural psychotherapy experience for junior psychiatrists (The Royal College of Psychiatrists, 1971, 1986). One way in which the College's recommendations can be achieved is by the appointment of a senior psychiatrist who devotes much of the working week to providing clinical supervision for junior doctors. The organisation and delivery of training in behavioural and dynamic psychotherapy within the South West Thames Region is described elsewhere (Crisp, 1977; Crisp et al, 1987; Stead et al, 1980). A peripatetic senior lecturer can provide much of the training and supervision and can mobilise other professionals to assist in this. In our own Region, there are two peripatetic senior lecturers, one for behavioural and one for dynamic psychotherapy, who each have eight sessions for teaching and academic duties and three sessions for clinical work. We suggest that other regions might like to adopt similar models for providing training in this important part of psychiatrists' training.

\section{References}

CRISP, A. H. (1977) Delivery of postgraduate medical education - who pays? British Medical Journal, 1, 1397-1399.

- Burns, T., Drummond, L., Heavey, A., Lieberman, S., Norton, K. \& Powell, A. (1987). The Learning of Communication Skills and Psychotherapy by Doctors Training in Psychiatry and Preparing for Entry into Higher Specialist Training in the South West Thames RHA. Report of a working party set up by the Psychiatric Sub-Committee of the South West Thames Regional Postgraduate Medical Committee, 33 Millman Street, London WCIN 3EJ.

DRUMmond, M. \& BHAT, A. V. (1987) A regional survey of the training of junior psychiatrists in behavioural psychotherapy. Bulletin of the Royal College of Psychiatrists, 11, 126-128.

HAFNER, R. J., LIeberman, S. \& CRisp, A. H. (1977) A survey of consultant psychiatrists' attitudes to their work with particular reference to psychotherapy. British Journal of Psychiatry, 131, 415-419.

Lieberman, S., HAFNER, R. J. \& CRISP, A. H. (1978) Teaching psychotherapy in mental hospitals. British Journal of Psychiatry, 132, 398-402.

MARKS, I. M. (1981) Cure and Care of Neurosis: Theory and Practice of Behavioural Psychotherapy. New York: John Wiley \& Sons

SteAd, J. S., Dick, G. W. A., Crisp, A. H. \& Viner, R. S. (1980) General professional training in psychiatry in the South West Thames Region. British Medical Journal, 281, 979-981.

The Royal College of Psychiatrists (1971) Guidelines for the training of general psychiatrists in psychotherapy. British Journal of Psychiatry, 119, 555-557.

(1986) Guidelines for the training of general psychiatrists in psychotherapy. Bulletin of the Royal College of Psychiatists, 10, 286-289. 